\title{
Monitoring system planned for US biodiversity drive
}

[SAN DIEGO] US efforts to create a Biodiversity Observatory Network (BON) are gathering speed as part of a biocomplexity initiative launched earlier this year by Rita Colwell, director of the National Science Foundation (NSF).

The proposed network of up to 20 sites across the country would serve as 'weather stations' to monitor ecological and systematic factors over time, link data through computer systems, and compare findings to historic collections at museums and universities.

The BON proposal is part of a plan for a National Ecological Observatory Network (NEON), a broader monitoring system on which the NSF's governing body, the National Science Board, was briefed last month. Next week, the NSF will hold its latest workshop on BON in San Francisco, where scientists will try to resolve different approaches to biodiversity research.

Although funding amounts have not yet been proposed, federal officials say that $\mathrm{BON}$ could require budget requests of $\$ 30$ million to $\$ 50$ million a year for three years to create the network's infrastructure, plus five-year operational grants of more than $\$ 500,000$ a year for each site, and $\$ 5$ million to $\$ 20$ million annually for associated research grants.

Colwell has requested $\$ 50$ million for the biocomplexity initiative for the 2000 fiscal year, and intends to expand it further thereafter. But it is not clear that the Republican Congress, which killed a previous administration effort to found a National Biological Survey, will support such an expansion of support for ecology and systematic biology.

BON would be one of the most ambitious initiatives to date by the NSF's division of environmental biology, part of the directorate of biological sciences. The BON sites would be at locations owned by governments, universities or non-profit organizations.

Attempts to use the effort to survey private lands could stir political objections. Conservatives in the Congress have opposed funding for such studies, on the grounds that they encroach on private property rights.

"BON is a test component of NEON," says Bruce P. Hayden, professor of environmental science at the University of Virginia, who serves as the NSF's director of the division of environmental biology until July.

The NSF has sponsored two workshops on $\mathrm{BON}$, with the third due to take place next week at the California Academy of Sciences. This is expected to address what one participant calls "the bond of marriage of ecology and systematics". Ecologists and systematists - who collect and classify specimens "aren't ready to go to the altar yet", notes one

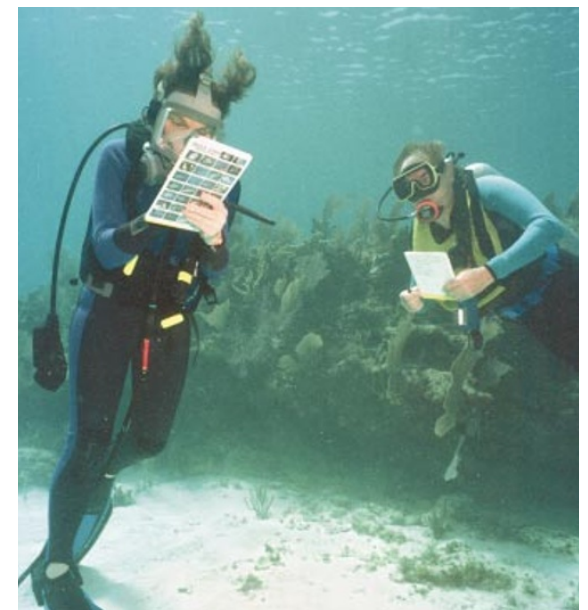

Diving for data: counting fish numbers - as here in Florida - will provide one source of input.

observer, adding that there is "a contentious" debate over their different approaches.

$\mathrm{BON}$ would record changes in the biota, reflect the chemical compositions of substances and assist in describing the origins of human diseases. The NSF hopes to combine the systematists' collecting capabilities with the ecologists' long-term analyses to produce an evolving picture of biodiversity at the sites. "If we can't work together, this thing won't float," says Hayden.

Many institutions and scientists are already involved in planning initiatives to lay the groundwork for BON, which NSF officials describe as moving at an "unprecedented" speed. Depending on funding, requests for proposals related to BON could come next year, say officials. For example, a consortium is forming to position its members to play key roles if funding is forthcoming.

Hatched in December at a conference on biodiversity modelling in San Diego, the nascent consortium involves universities in the United States and Mexico, museums in the United States and Canada, the San Diego Supercomputer Center, the NSF's 21-site Long Term Ecological Research Network, based at the University of New Mexico, and the National Center for Ecological Synthesis and Analysis in Santa Barbara.

Leonard 'Kris' Krishtalka, director of the University of Kansas Natural History Museum and a leader in forming the consortium, says the group is using an NSF grant that involves many of the same institutions as "a springboard" to be ready for BON. "No one institution has the mission, infrastructure and experience to do what is necessary," he says. "Solving the complexity of research riddles of biodiversity is going to require synthesis and collaboration."

Rex Dalton

\section{NASA's plan to hire peer-review contractor raises scientists' fears}

[WASHINGTON] A plan by the US space agency NASA to hire a single contractor to manage the peer review of all its research grant proposals has made some scientists worried that the quality of review will suffer during the transition period.

The agency hopes to invite small, minority-owned businesses this summer to bid for a 'consolidated peer review' contract to administer the outside evaluation of grant proposals in space science, Earth science, life and microgravity science, equal opportunity programmes, and education. Currently each office handles its own peerreview logistics, with about 5,000 proposals considered across the agency each year.

NASA intends to award a five-year contract worth more than $\$ \mathbf{5 0}$ million by next February. The agency's move to consolidate peer review follows a recent push to streamline its headquarters management and speed up the processing of grants (see Nature 393, 403; 1998).

But several scientists voiced their concern about the plan during last week's meeting of NASA's external advisory group for life and microgravity sciences. They worry that hard-won improvements to the existing peer-review system, which have raised the reputation of NASA experiments and brought them more in line with research conducted by the National Institutes of Health, will be jeopardized if the new contractor lacks experience.

"If we start going backward, what credibility has been built up may be lost," said Kenneth Baldwin of the University of California at Irvine, the chairman of NASA's life sciences advisory subcommittee. Gerard Faeth of the University of Michigan, who chairs the subcommittee for microgravity science, called the consolidation "probably the most critical issue for my constituency".

Those two disciplines have much at stake, as the office for life and microgravity sciences now gives responsibility for peer review - including selecting and presiding over review panels - to its contractor, Information Dynamics, Inc. of Virginia.

In contrast, NASA's space science office handles some of its peer-review duties inhouse. Science research programme director Guenter Riegler says that consolidation could benefit his office by providing more contractor help to a small group of NASA civil servants. But managing the transition will be the difficult part, says David Bohlin, who runs the peer-review process for space science. "We have to keep the system operating while we [shift to a single contractor]," he says. 